\title{
LA CONSTRUCCIÓN CON CERÁMICA ARMADA. IGLESIA DE SAN JUAN DE ÁVILA, EN ALCALÁ DE HENARES/ESPAÑA
}

\author{
(BUILDING WITH REINFORCED CERAMICS. SAN JUAN DE ÁVILA CHURCH, IN \\ ALCALÁ DE HENARES/SPAIN)
}

Juan de Dios de la Hoz Martínez y Carlos Clemente San Román, Arquitectos

ESPAÑA

Fecha de recepción: 29-XII-97

$148-165$

\section{RESUMEN}

La iglesia de San Juan de Ávila, en Alcalá de Henares, es uno de los primeros edificios construidos por Eladio Dieste en Europa.

Se trata de un templo levantado con la técnica de cerámica armada en la cual se confia la resistencia a compresión a la fábrica de ladrillo, mientras que las armaduras de las juntas permiten resistir las tracciones e, incluso, favorecer el sistema constructivo.

\section{SUMMARY}

San Juan de Ávila, in Alcalá de Henares, Spain, is among the first buildings in Europe built by Eladio Dieste.

It is a temple constructed with the thecnique of reinforced ceramics where the compression strength is beared by the brick masonry, while the reinforcement of the joints allows bearing the traction strength and even favours the constructive system.

“... un ingeniero que encontró con que al construir grandes galpones, estaba haciendo arquitectura aunque no me lo propusiera; que tenia, además, consciencia de la forma y de que ésta no me huí, me hablaba y al hablarme me ayudaba a resolver problemas estrictamente estructurales."



Eladio Dieste

Fachada principal con el rosetón, de Carlos Muñoz de Pablos.

(c) Consejo Superior de Investigaciones Científicas 


\section{LA CONSTRUCCIÓN CON CERÁMICA ARMADA}

Tras algunos años, en los que por diversos problemas, ecónómicos en algunos casos y de tiempo y precipitación en otros, se iba a la búsqueda eufórica del local parroquial mínimo en el que poder celebrar una misa dominical (sótanos, bajos comerciales e incluso pisos), los últimos años están suponiendo un indudable impulso en la construcción de nuevas iglesias, capillas e incluso catedrales en todo el mundo y en España. Indudablemente la arquitectura religiosa ha sido, históricamente, un referente para todos aquellos interesados en cualquiera de las nobles artes y aún más, en el caso de España, no es menos cierto que ésta debe ocupar un lugar preferente en la arquitectura de postguerra y recientemente se vuelve a escribir, proyectar (el caso paradigmático reciente es el concurso de las iglesias para el Jubileo en Roma) o debatir sobre los edificios religiosos, sobre la colaboración entre los diversos artistas y sobre las experiencias acontecidas en casos anteriores. Los nuevos templos de la Diócesis de Alcalá de Henares buscan, por un lado, renovar este debate $y$, por otro, construir unos edificios desde la técnica y la economía, con el resultado final de imbricación en la liturgia y en el uso. Es por esto por lo que dichos edificios se han proyectado y construido con técnicas de cerámica armada en colaboración con el taller de Dieste \& Montañez del ingeniero uruguayo Eladio Dieste.

El material cerámico permite su ubicación con extrema sencillez, racionalidad técnica y constructiva y, sobre todo, económica, permitiendo el conocimiento de algunas premisas básicas de la arquitectura “...Para que la arquitectura sea de veras construida, los materiales no deben usarse sin un profundo respeto a su esencia y, consiguientemente, a sus posibilidades...". El uso del ladrillo permitía, además, la recuperación de un sistema constructivo, e incluso de una tipología de edificios, que se había mantenido en el entorno alcarreño -de clara influencia toledana- durante siglos. Por otra parte, incluso los propios conceptos o creencias religiosas coincidían en el finúltimo “...Creo que lograríamos un amplio acuerdo si pusiéramos como fin compartible la plenitud y felicidad del hombre... No me importa el poder, me importa el hombre..." (Eladio Dieste. Montevideo, 1979).

La colaboración con Eladio Dieste permitió el primer acercamiento a los métodos de diseño, los sistemas constructivos e incluso los primeros cálculos de estructuras laminadas. La inclusión de pequeñas estructuras en algunos de los edificios contribuyó a la necesaria experiencia constructiva y técnica necesaria para estas obras y sobre todo permite la confianza necesaria en las empresas encargadas de su realización. Estas estructuras fueron una bóveda de arco de círculo del edificio Nebrija, de Metropolitana Complutense, en Alcalá de Henares y sobre todo el muro calado y la torre de comunicación vertical de la planta de química fina en el Campus de la Universidad de Alcalá de Henares. Estas experiencias permitieron comprobar no sólo el interés de estas formas, su luz, sino también la realidad económica de las mismas; la sencillez de cálculo y de construcción que se hizo patente incluso por la presencia del propio Eladio Dieste en las mismas para indicar el proceso y la técnica de montaje de encofrados, redondos, ladrillos, etc.

La técnica utilizada permite, por una parte, unos enormes rendimientos y, por otra, una gran facilidad de los sistemas, de los medios auxiliares y del control de la ejecución de las obras. Además de esto, los edificios presentan valores añadidos de tipo estético, de funcionalidad, perfecto mantenimiento y buen funcionamiento litúrgico. En general, el item es simple y puede asimilarse a un sistema casi de prefabricación, ya que se repite a diario el encofrado, el montaje de todas las piezas cerámicas, posteriormente se rellenan las juntas, se introducen las varillas en las juntas en ambas direcciones, se extiende el mallazo, se vierte y allana la capa de compresión y se pone en carga el tirante horizontal de cada bóveda. Al día siguiente se desencofra y se baja mediante unos sencillos gatos; se corre el encofrado (que, naturalmente, es para todas las puestas de las bóvedas de la obra) sobre unos carriles, dejándolo de nuevo preparado para repetir el proceso y realizar una nueva bóveda a partir de las esperas del día anterior. Para toda esta operación son necesarios 4 albañiles colocando ladrillos y tres peones sirviéndoles material, más el gruísta y el encargado. Además de la sencillez y de la facilidad del trabajo seriado, podemos aumentar estos rendimientos; a través de medios auxiliares y elementos de apoyo a los trabajos (gatos, compresores, grúas, etc.) más industrializados y de más rápido y fácil manejo. Estas técnicas, de las que Dieste en Uruguay, Brasil, etc., ha perfeccionado con los años, buscaban, según nos hablaba él mismo, no sólo construir edificios, sino procurar, además, profundizar en el arte, en la ciencia, en el sentido del hogar que existe en las tierras, en los campos y en los hombres que lo habitan.

Este tipo de edificios constituye un sistema de trabajo con la arquitectura que viene marcada por la investigación y el fundamento de las cosas. Las construcciones en ladrillo con la técnica de la cerámica armada revela, a las claras, su procedencia y muestra sin artificios su significación como hecho proyectual, constructivo. En lo referente al espacio religioso, se percibe un atractivo espacio construido cuyos protagonistas son los usuarios.

La construcción de los primeros edificios en Europa de Eladio Dieste con la técnica de la cerámica armada se ha apoyado en la sólida experiencia de éste, con más de un millón de metros cuadrados construidos en el continente americano, y en el análisis de la iglesia de Atlántida, para estudiar su sistema constructivo, 
"recuperándolo" en España y la rehabilitación de Durazno ecléctico, fue también objeto de estudio. El conocimiento de estas obras, su estudio y puesta en obra en España, nos ha permitido ir sobre seguro en el conocimiento de las técnicas, los problemas, la construcción, los rendimientos, la economía, etc., de las mismas. Tras estos dos modelos iniciamos, a partir de los bocetos de la no realizada iglesia de Dieste en Malvín, un proyecto para la iglesia de San Juan de Ávila en Alcalá de Henares, que recogía parte de los criterios iniciados por Dieste en Uruguay, pero con un proyecto nuevo que le presentamos y en el que desde el primer momento puso - y nosotros con él- todo su empeño, en estrecha colaboración, para su redacción. El último eslabón, de momento, es la próxima construcción de dos nuevas parroquias proyectadas enteramente desde España, con estas técnicas constructivas y los mismos criterios de economía, racionalidad, unidad espacial constructiva, etc. Estas dos iglesias (Santa Cruz en Coslada y Nuestra Señora de Belén en Alcalá de Henares) suponen una etapa más en estos cinco años de relación con Dieste, en los que su contribución -sobre todo técnica, con los criterios compositivos discutidos frecuentemente- ya no es el de proporcionar unos modelos (que indudablemente han servido, y así se plantearon, para hacer viable la construcción), sino el de proyectar bajo los criterios tanto técnico-constructivos, economía, sencillez y tensión de los esfuerzos que las harán posibles. (...'La audacia producía en las gentes no desconfianza, ni sólo sorpresa, sino felicidad; distinguían muy bien la diferencia entre lo que es importante por el tamaño o por el coste, de aquello que nos toca en lo más hondo porque nos expresa el esfuerzo que lo produjo. No les satisface que una dificultad se resuelva a base de dinero, sino más bien que se salve con facilidad, con la dulzura que adquieren las manos más rudas cuando acarician la cabeza de un niño" Eladio Dieste. Montevideo, 1973).

Si revisamos las décadas del siglo, deteniéndonos en el terreno de los edificios religiosos, se han dado hermosísimos ejemplos basados, en la mayoría de los casos, en criterios como el anterior. En España, iglesias como la nueva Basílica de Aránzazu, de F.J. Saenz de Oiza, la iglesia de Pont de Suert, de E. Torroja y Rodríguez Mijares, la iglesia de los Dominicos de Arcas Reales, en Valladolid, de M. Fisac, la capilla del Colegio Aquinas, en Madrid, de J. García de Paredes y R. de la Hoz, la de Villalba, en Ciudad Real, de José Luis Fernández del Amo o la capilla de la Fundación Gironella - Mundet en Barcelona, de M. Baldrich son referentes de un tipo de arquitectura que, sin duda, ha pesado en las últimas generaciones de arquitectos y cuyas influencias se han recogido en otros edificios.

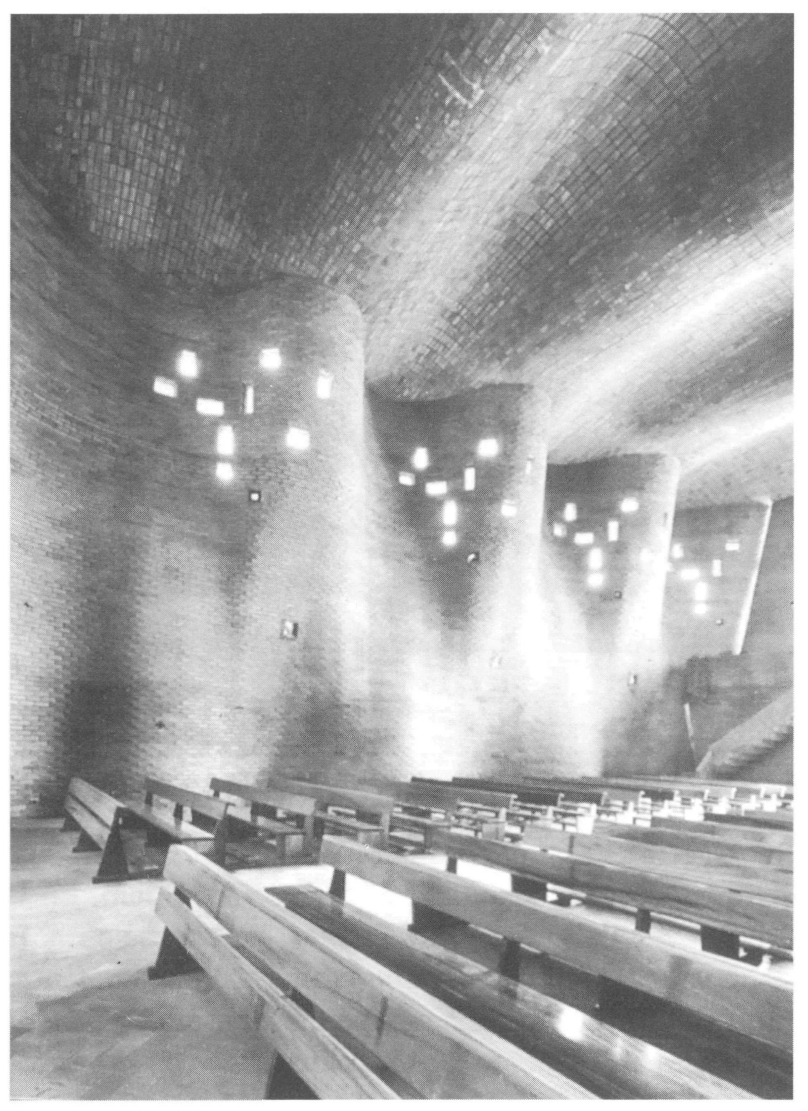

Vista del interior del presbiterio hacia la cubierta y la cruz de la fachada.

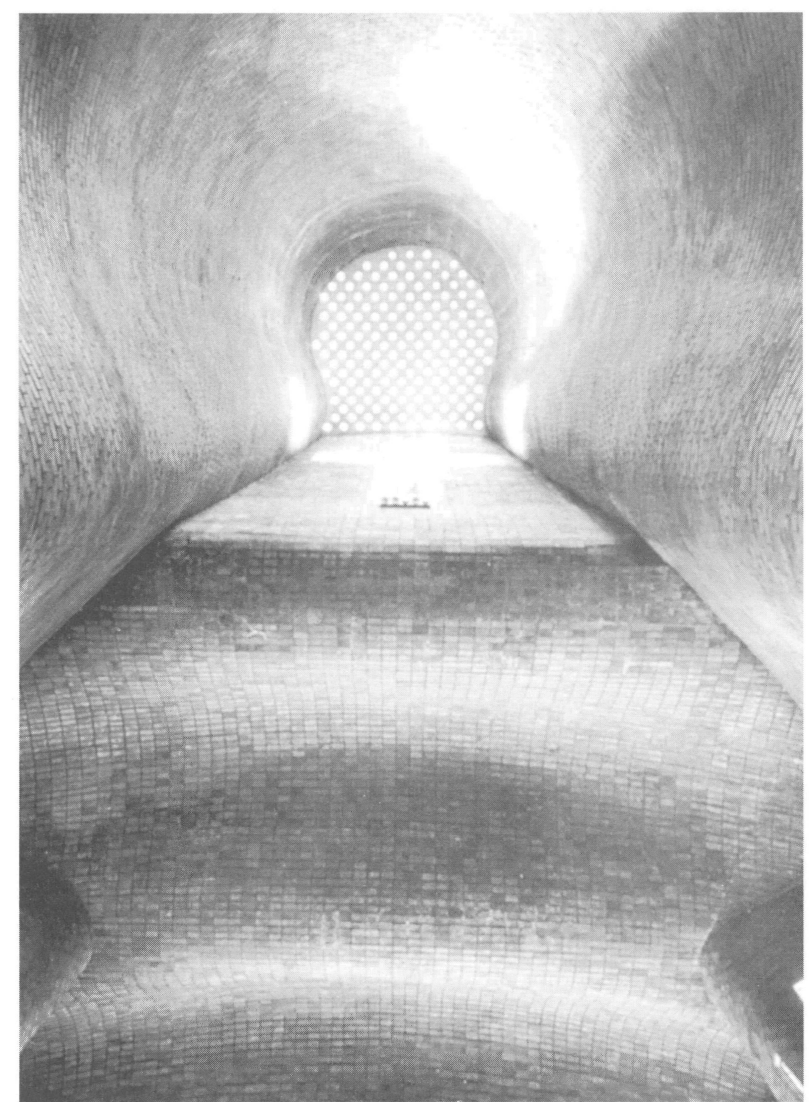

Interior de la nave de la iglesia. 


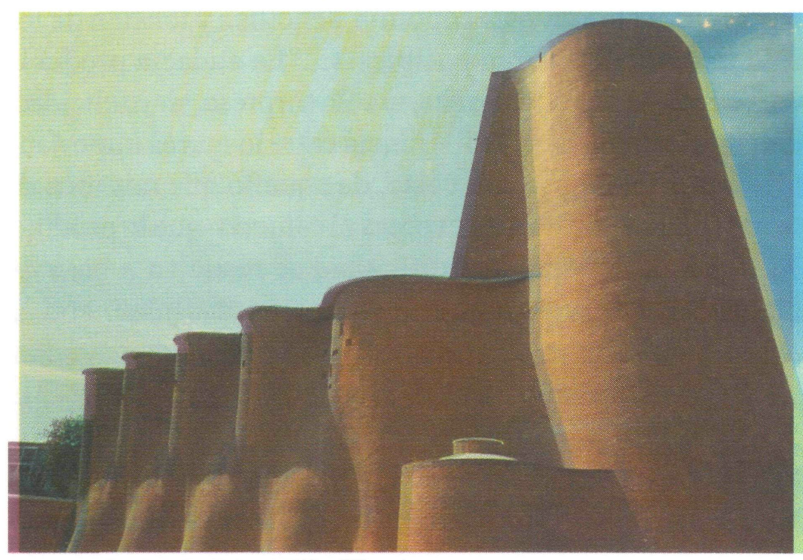

La nave y el presbiterio desde el noreste.

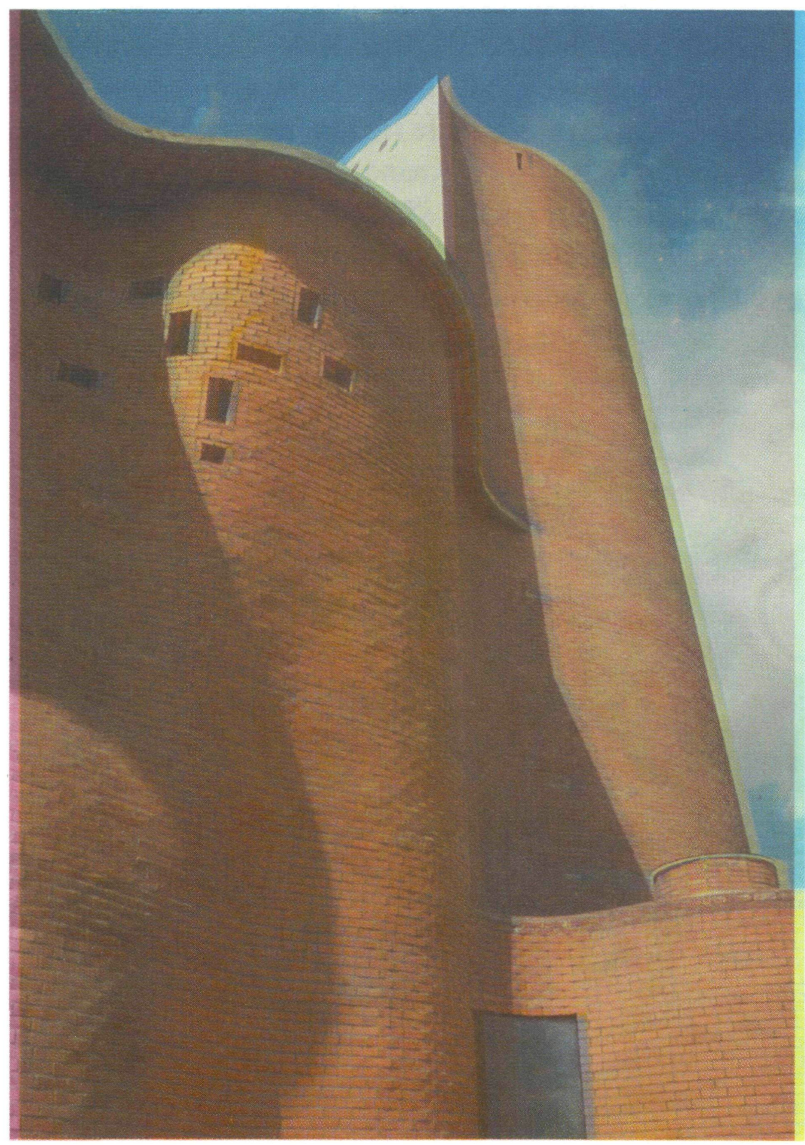

Detalle del encuentro de la sacristía, nave y presbiterio.



Vista general con el volumen de la nave y el presbiterio y cruz.

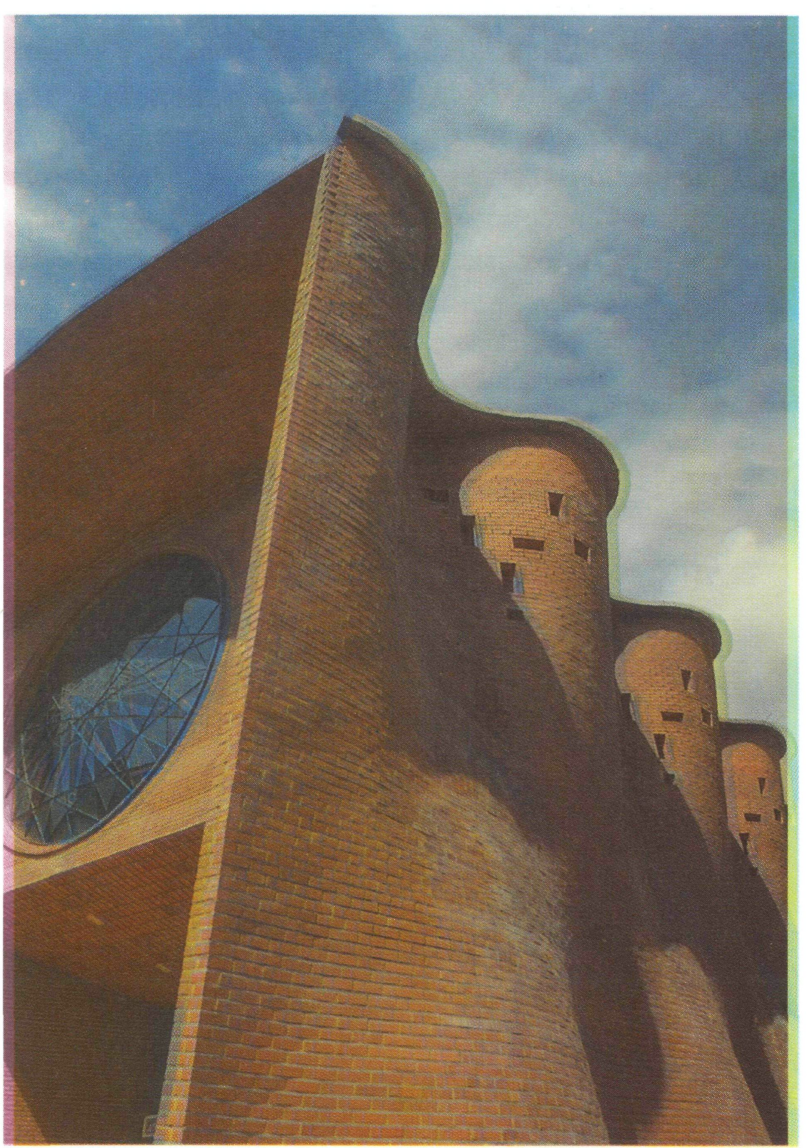

Detalle de los muros laterales y zuncho de cubierta.

(Como ejemplo, baste indicar que Atlántida se empezó a construir en 1954; Durazno en 1968, mientras que Le Corbusier realiza Ronchamp en 1955). Las experiencias centroeuropeas de O. Wagner (Am Steinhof, en Viena, 1907), Auguste Perret (Nuestra Señora, en Raincy, 1918), Karl Moser (San Antonio, en Basilea, 1927) y, sobre todo (debido, con toda probabilidad, a los enormes destrozos de la guerra y, por tanto, a la necesidad de

construcción de nuevos edificios), los alemanes Rudolph Schwarz, Emil Steffann, O. Bartning y D. Böhm. En la mayor parte de los ejemplos citados, la renovación y la técnica moderna conviven con la liturgia, con el afán de construir con lógica y sinceridad sobre la base de los nuevos materiales. Sus valores estarán, al igual que en la obra de Dieste, en el orden, la sencillez, la proporción, la técnica y la luz. 

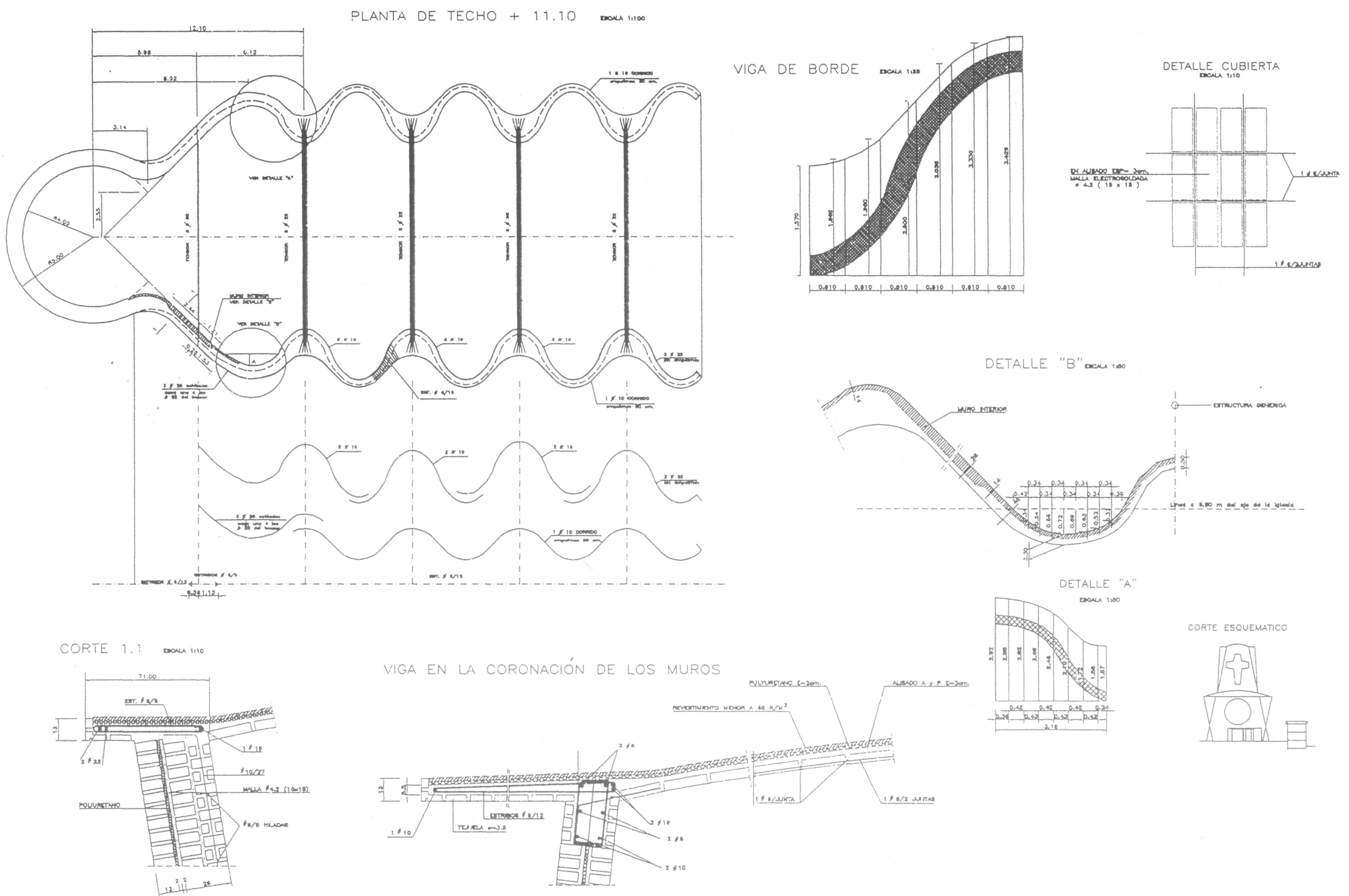

detalle "A"
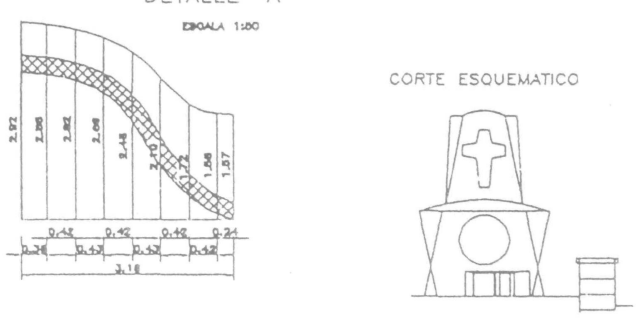

Planta de la iglesia con los detalles de armadura de las bóvedas, zunchos y tirantes. 


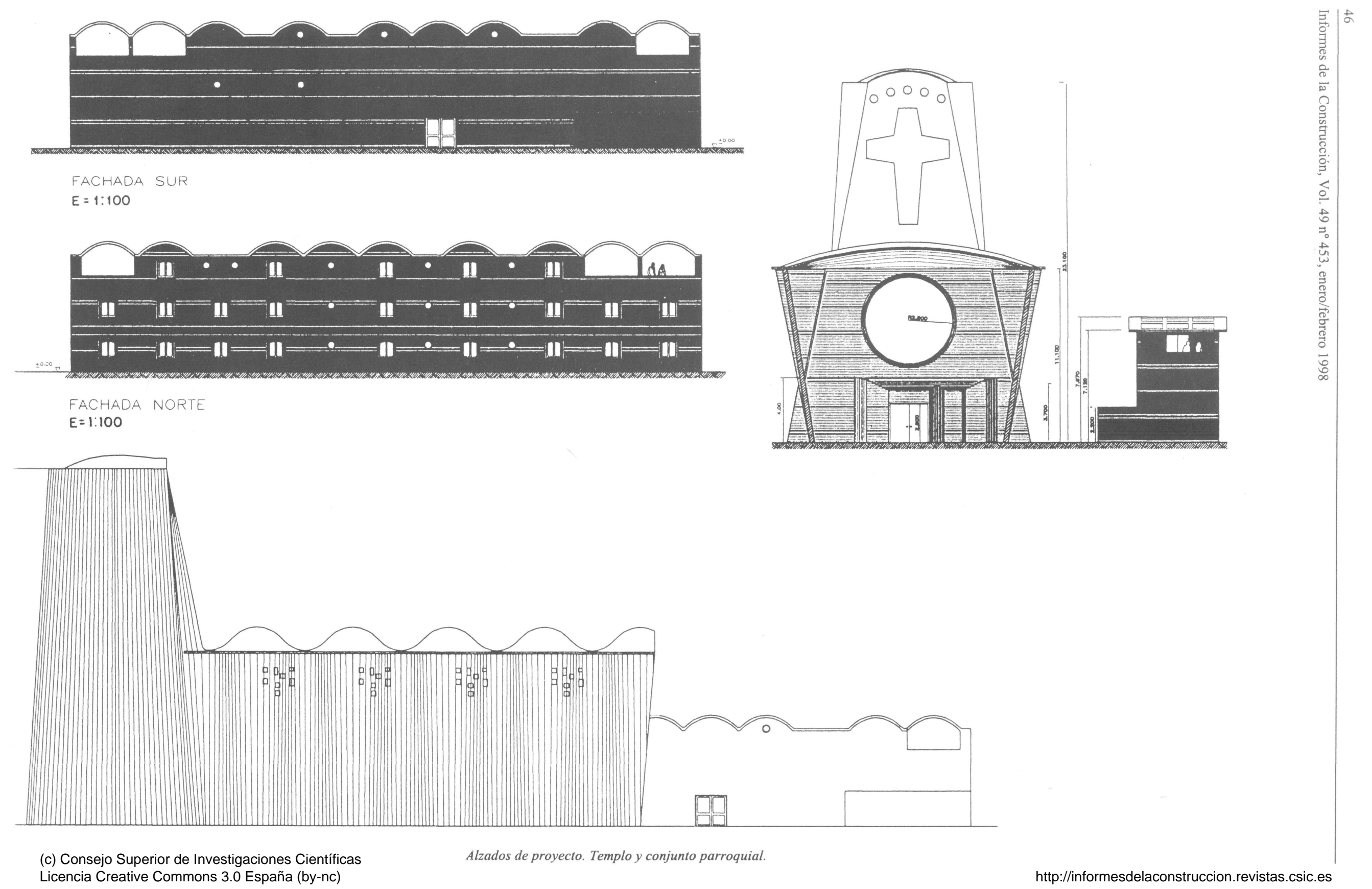


En la nueva iglesia de San Juan de Ávila, en Alcalá de Henares, se aglutinan (quizá, en muchos casos, inconscientemente) gran parte de los referentes antes citados, huyendo también de esa construcción monótona, pobre, anónima o sin cualidades espaciales que, desgraciadamente, pueblan y degradan nuestros entornos edificados. Se trata de un edificio que, a nivel estructural, responde a un esquema simple: Crear un sistema de láminas muy finas, pero lo suficientemente rígidas para evitar los tirantes vistos por lo que debe resistir tanto los esfuerzos de flexión como los de compresión (unido además a que su peso haga que permanezca, sin alteraciones importantes, su estado tensional cuando se modifican las condiciones de carga).

Es por esto, que las formas que la iglesia presenta, nunca pueden considerarse gratuitas o vacías. Por su propia geometría confieren a la estructura capacidad para resistir las solicitaciones a las que se le somete y además deben ser geométrica y técnicamente aplicables a un proceso constructivo concreto, de fácil tecnología y replanteo. El estudioso o el técnico avezado descubrirá además el porqué de las reducciones de las secciones hasta las que presenta San Juan de Ávila (la bóveda tiene un espesor total de nueve centímetros), ya que la colocación del ladrillo "a tabla" con las juntas coincidentes, permite la colocación de un fino redondo de acero en cada una de las juntas (en las dos direcciones) de forma que se crea un entramado de acero capaz de absorber las flexiones e incluso favorecer el proceso constructivo, evitando las mayores dilataciones durante el fraguado. Además, se acentúa claramente el parámetro también económico, ya que es posible, con sólo idear un sencillo artilugio semejante a un raíl de tren más unos gatos, utilizar el mismo encofrado para todas y cada una de las bóvedas de la iglesia, que, como ballenas varadas, se alinean en la dirección transversal a la del eje mayor. Los muros no son tersos, sino rugosos. Se aprecian las esquinas de los ladrillos en cuanto la curvatura de los muros impide que se adapte la medida de uno o medio pie. Todos los ladrillos utilizados en la iglesia de San Juan de Ávila proceden de Navas de la Asunción, en Segovia, y fueron sometidos a diversas pruebas antes del inicio de la obra, comprobándose que ofrecían una resistencia a compresión mayor de $200 \mathrm{~kg} / \mathrm{cm}^{2}$, sin heladicidad y con baja salinidad. La cerámica ofrecía multitud de posibilidades dependiendo del tipo de material que quisiéramos usar, ya que se disponía, prácticamente, de cualquier grosor, tipo, macizado, etc. Se tomó entonces un ladrillo perforado de $7 \mathrm{~cm}$ de espesor para toda la fábrica resistente de los muros de la iglesia, mientras que el ladrillo utilizado en la fábrica de la fachada principal es perforado, de $5 \mathrm{~cm}$ de espesor y el de las cubiertas, dinteles, recercados, etc., macizo, de $5 \mathrm{~cm}$ de espesor, igualmente.

La construcción de la iglesia (realizada en nueve meses de trabajo) se inició con el replanteo a nivel del terreno para ejecutar la zanja de cimentación. Dicha zanja responde también al mismo diseño de superficies suaves y onduladas, pudiendo realizarse por métodos sencillos y convencionales. En este caso se realizó una excavación de 80 x $100 \mathrm{~cm}$ para alojar en la misma una zapata corrida con una cuantía de $25 \mathrm{~kg} / \mathrm{m}^{2}$. Sobre dicha zapata se replantearon las tres primeras hiladas ya con el ladrillo definitivo de los muros, mientras que, a doce metros de altura (y apoyado en dos andamios paralelos), se construía una plataforma de madera sobre la que se dibujaba el replanteo de las curvas de cubierta, que, en este caso, eran alternas con respecto a las del suelo (lo que a nivel de suelo era cóncavo, a nivel de

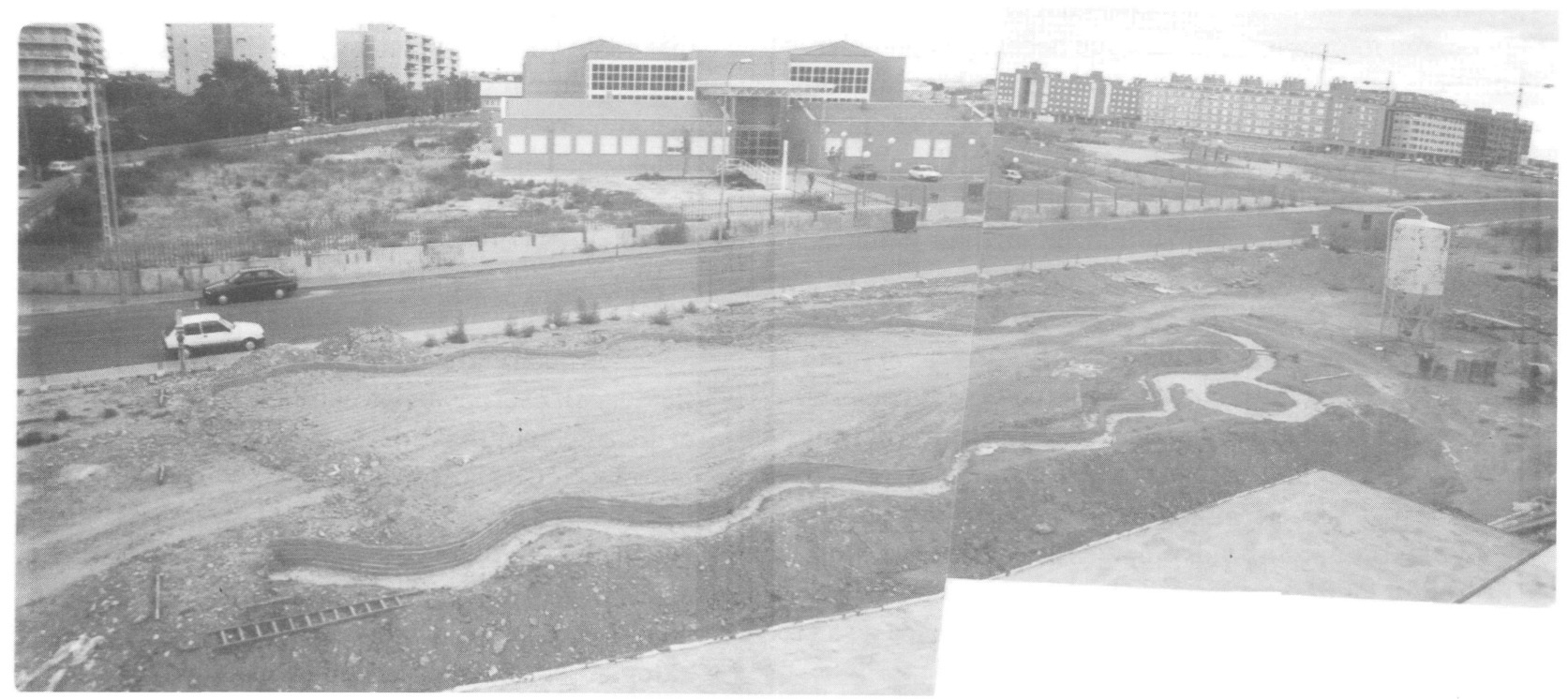

Replanteo de cimentación y arranque de muro. 


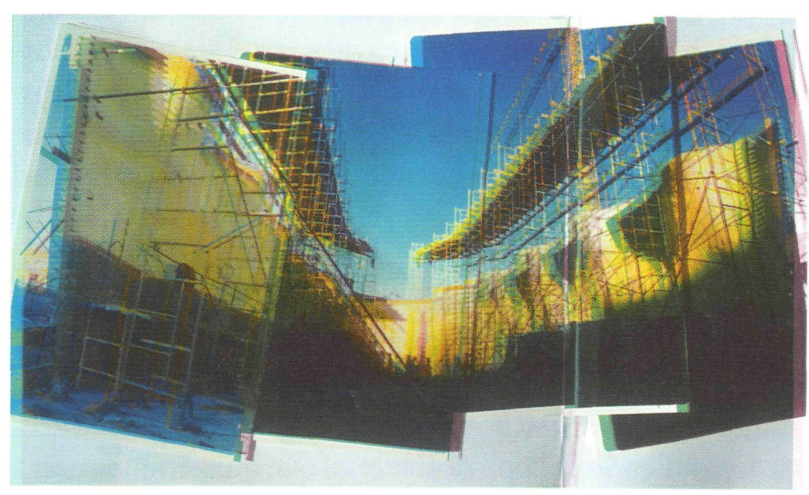

Vista general con la hoja exterior terminada.

cubierta era convexo y viceversa). Entre las dos curvas replanteadas sobre el suelo y la plataforma se tiraban los alambres necesarios que, apoyados en estas dos directrices, daban lugar a una auténtica superficie reglada. De esta forma, el albañil necesita emplear, únicamente, el nivel en una mano y la paleta en la otra, para ir colocando las diversas hiladas, apoyándose en los hilos que definen las superficies.

Los muros son de $30 \mathrm{~cm}$ de espesor en total y están construidos a base de dos medios pies entre los que queda un enfoscado sobre la cara exterior y, sobre éste, una capa de poliuretano proyectado, más una cámara de aire de unos $4 \mathrm{~cm}$. Para asegurar el correcto trabado de las dos hojas se van disponiendo llaves de acero de atado entre los dos muros, colocando una cada metro al tresbolillo. En este caso, no era necesaria armadura horizontal, pero como medida preventiva se situaron cada cuatro hiladas, unos redondos de $5 \mathrm{~mm}$, adaptándose en cada altura a la forma del muro. Además de esto, en el enfoscado se dispuso una fina malla de alambre de $3 \mathrm{~mm}$ en cuadrícula de $25 \times 25$. A pesar del enorme desplazamiento en la cabeza de los muros, en ningún momento de la obra fue necesario apuntalar los mismos; se mantenían perfectamente estables aún sin la cubierta que serviría de atado en cabeza de los dos extremos de los mismos. Una particularidad se observa en la "teja" que conforma el presbiterio, ya que en ella, la directriz inferior y superior es un círculo de distinto radio; cuya separación entre los muros de medio pie pasa de ser de 4 a $70 \mathrm{~cm}$, lográndose en el interior de los mismos un espacio sorprendente y mágico, que, además, permite la ubicación de la rampa catalana de acceso a las cubiertas y que actúa como llave de unión entre las dos hojas del muro.

Estas paredes se terminan en una gran viga de borde horizontal que absorbe los empujes de las bóvedas, aloja en su espesor los tirantes, permite la ejecución de las pendientes para la caída de las aguas y, finalmente, hace de alero.

Las cubiertas son bóvedas gausas y están formadas por una directriz -normalmente catenaria para que la componente

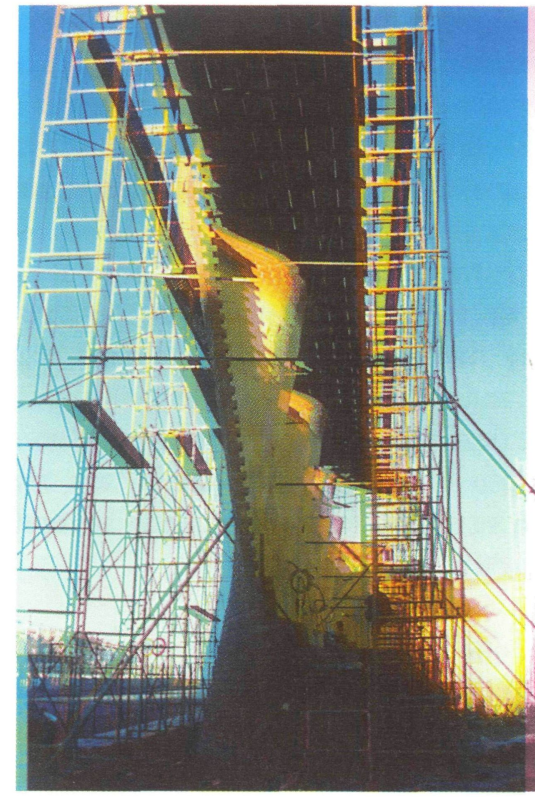

Detalle de la construcción de los muros.

de peso produzca compresión simple- que mantiene una cuerda fija, pero una flecha variable y que se va moviendo trasladándose sobre un plano vertical que se desplaza paralelamente cada vez, perpendicularmente a la luz máxima de la bóveda. Este sistema puede sofisticarse cambiando la directriz a dos ondulaciones obteniendo, así, ventanas transversales de forma parecida a la de un conoide - así se van a ejecutar en las futuras parroquias de Santa Cruz de Coslada y Nuestra Señora de Belén de Alcalá. La misma se ejecuta mediante un molde de madera que se construye por medio de una sucesión de "costillas" que no responden más que a la propia directriz moviéndose sobre el plano y sobre las que se colocan las tablas que conformarán la superficie y que tiene la sección necesaria para el cálculo (no es necesario señalar que cuanto más ondulación se le dé, más canto posee y, por tanto, más rígida es), sobre la que se dibuja primero y se coloca después, todo el damero de las piezas cerámicas, unidas entre sí mediante mortero y colocando en cada junta transversal y longitudinal un redondo de acero para asegurar su vínculo entre todas ellas, a fin de poder considerarla como una unidad (la armadura longitudinal vincula entre sí los distintos arcos evitando que salgan fisuras transversales entre cada uno de ellos, mientras que la armadura transversal sirve para resistir las flexiones). Esta operación debe iniciarse, lógicamente, con el llenado muy leve de la junta con mortero; posterior introducción de la armadura; a continuación, llenado de la junta hasta el borde del ladrillo embebiendo completamente la armadura y, finalmente, colocar un enfoscado de cemento en el que se introduce, además, un mallazo metálico. Cada una de estas bóvedas puede desencofrarse a las $24 \mathrm{~h}$. Como es lógico, el encofrado sirve para muchas veces, siendo sólo cuestión de tener que bajarlo con los gatos y desplazarlo hasta la siguiente bóveda sobre los carriles para subirlo, 
PLANTA TECHO mom noos
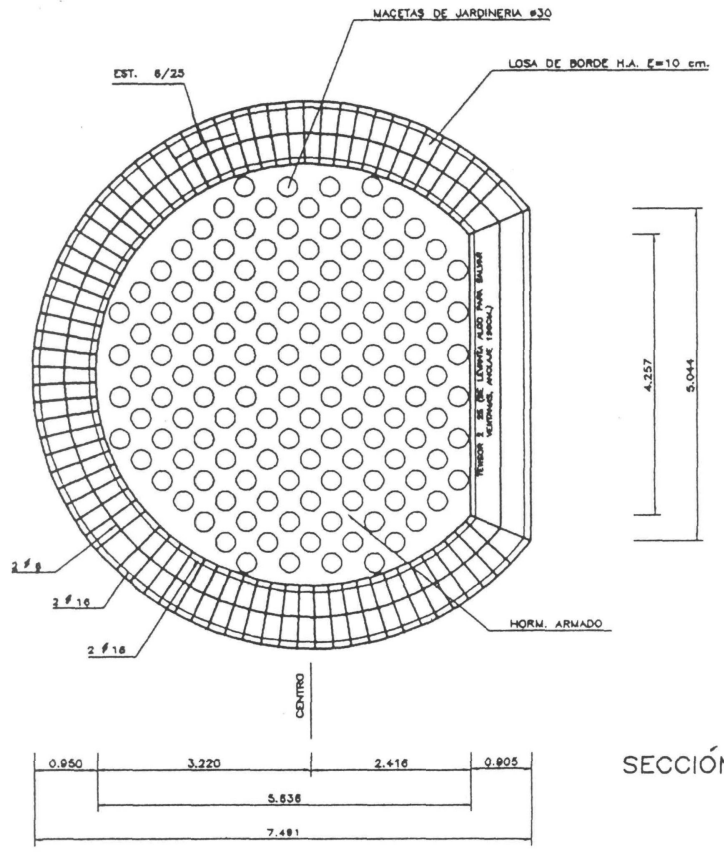

SECCIÓN "A"

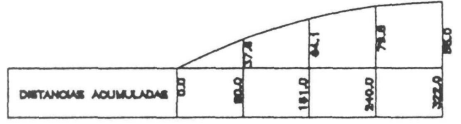

SECCIÓN "C"

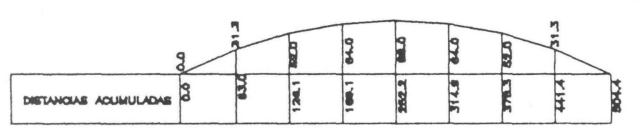

SECCIÓN "B"

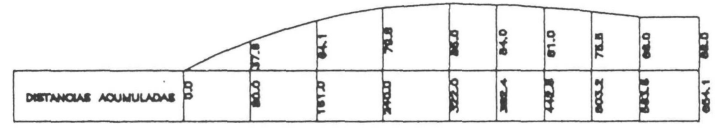

SECCIÓN "D"
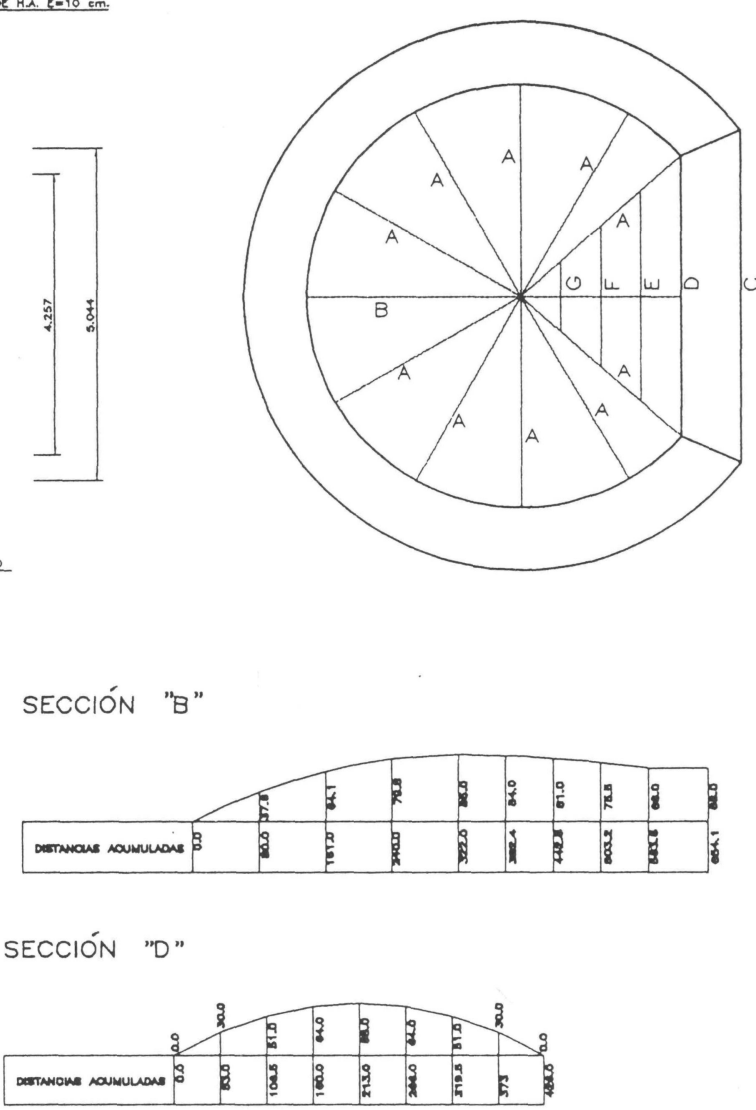

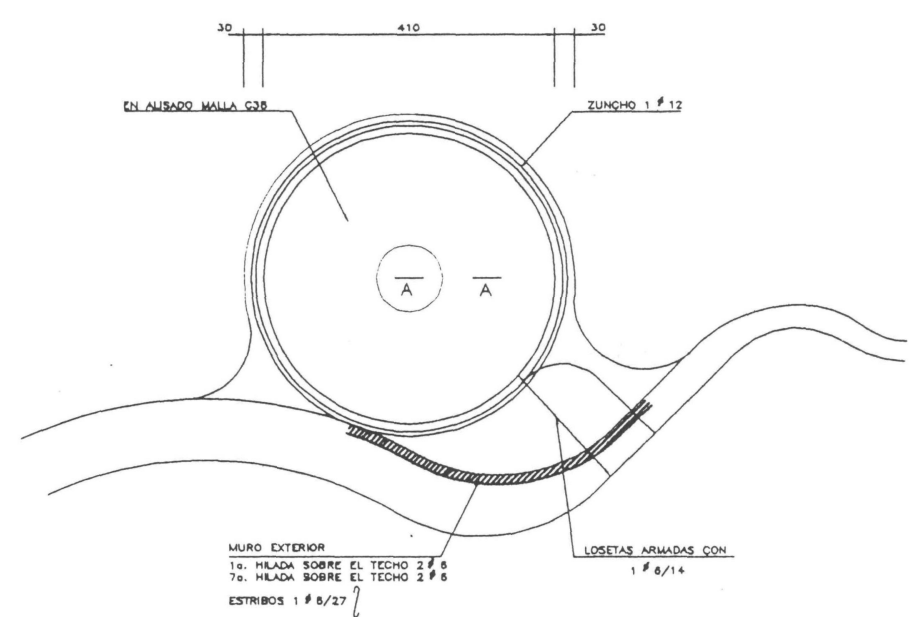

DETALLE CÚPULA PRESBITERIO
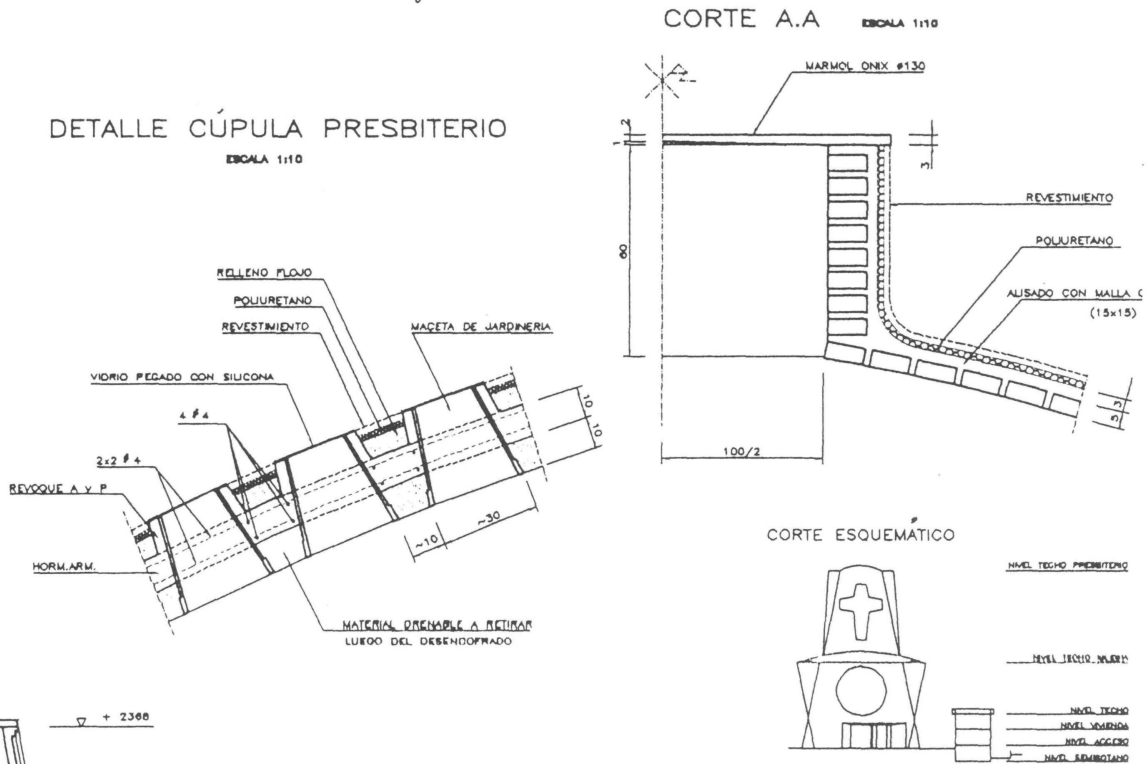

CORTE AXIAL in

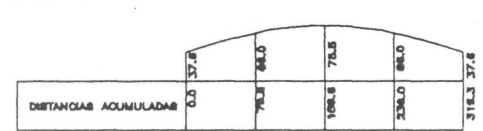

SECCIÓN "F"

SECCION "G"

$3 \%$

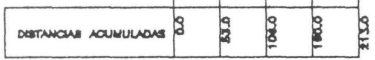

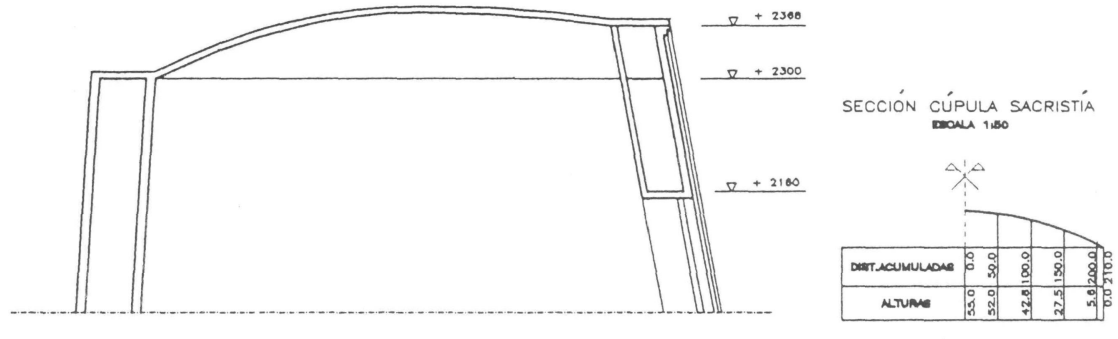

Detalles de las cubiertas del presbiterio y sacristía. 


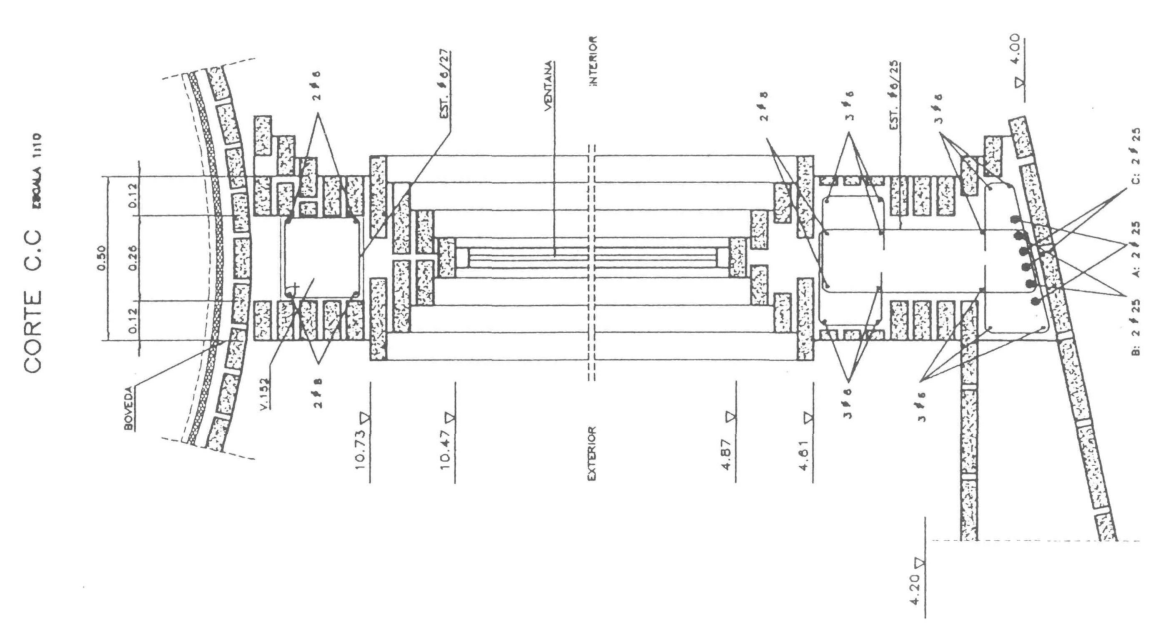

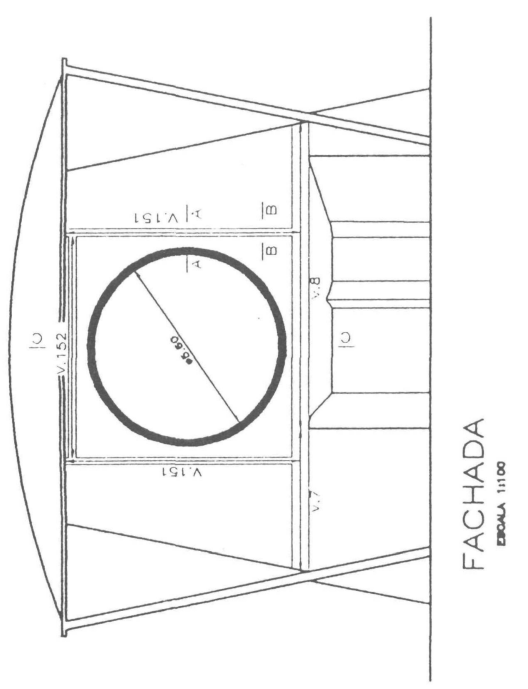
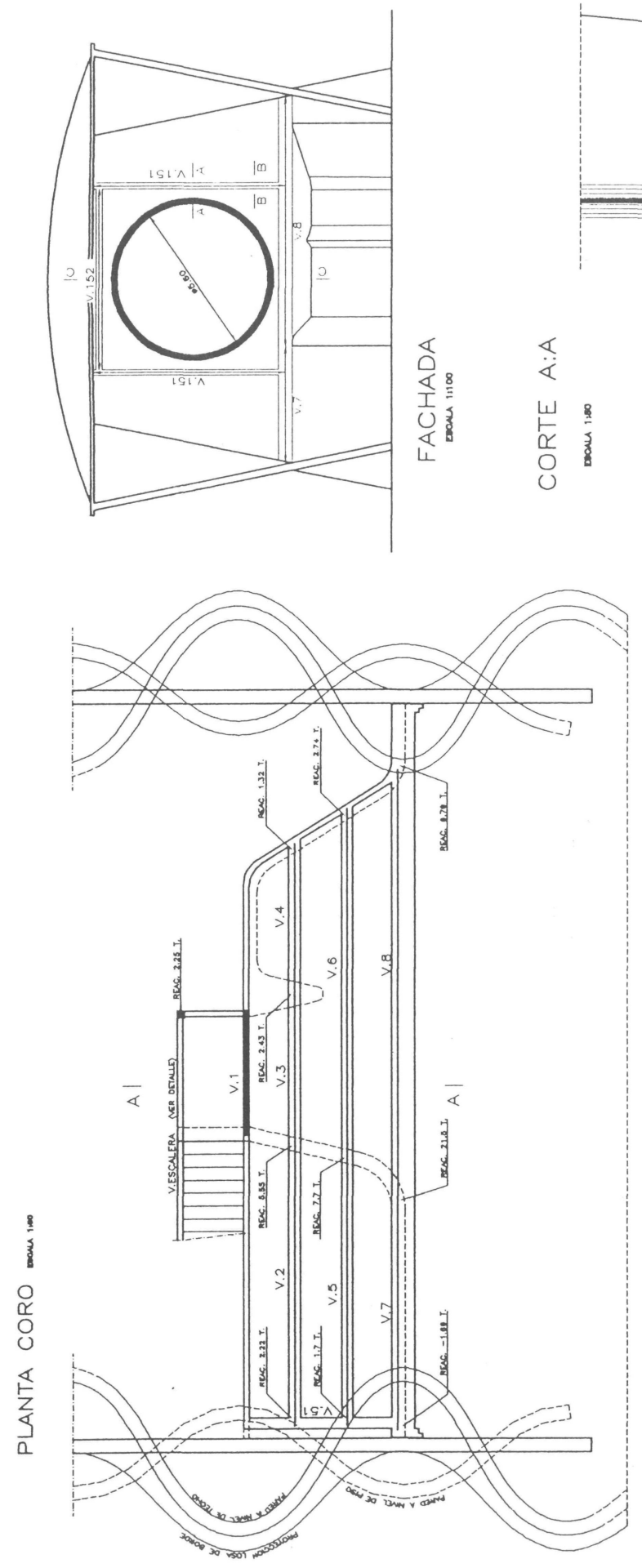

(c) Consejo Superior de Investigaciones Científicas Licencia Creative Commons 3.0 España (by-nc)
(1)

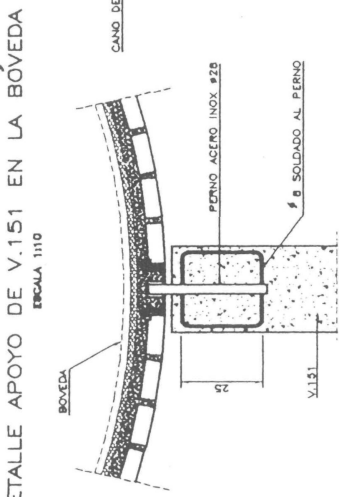

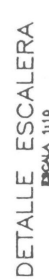
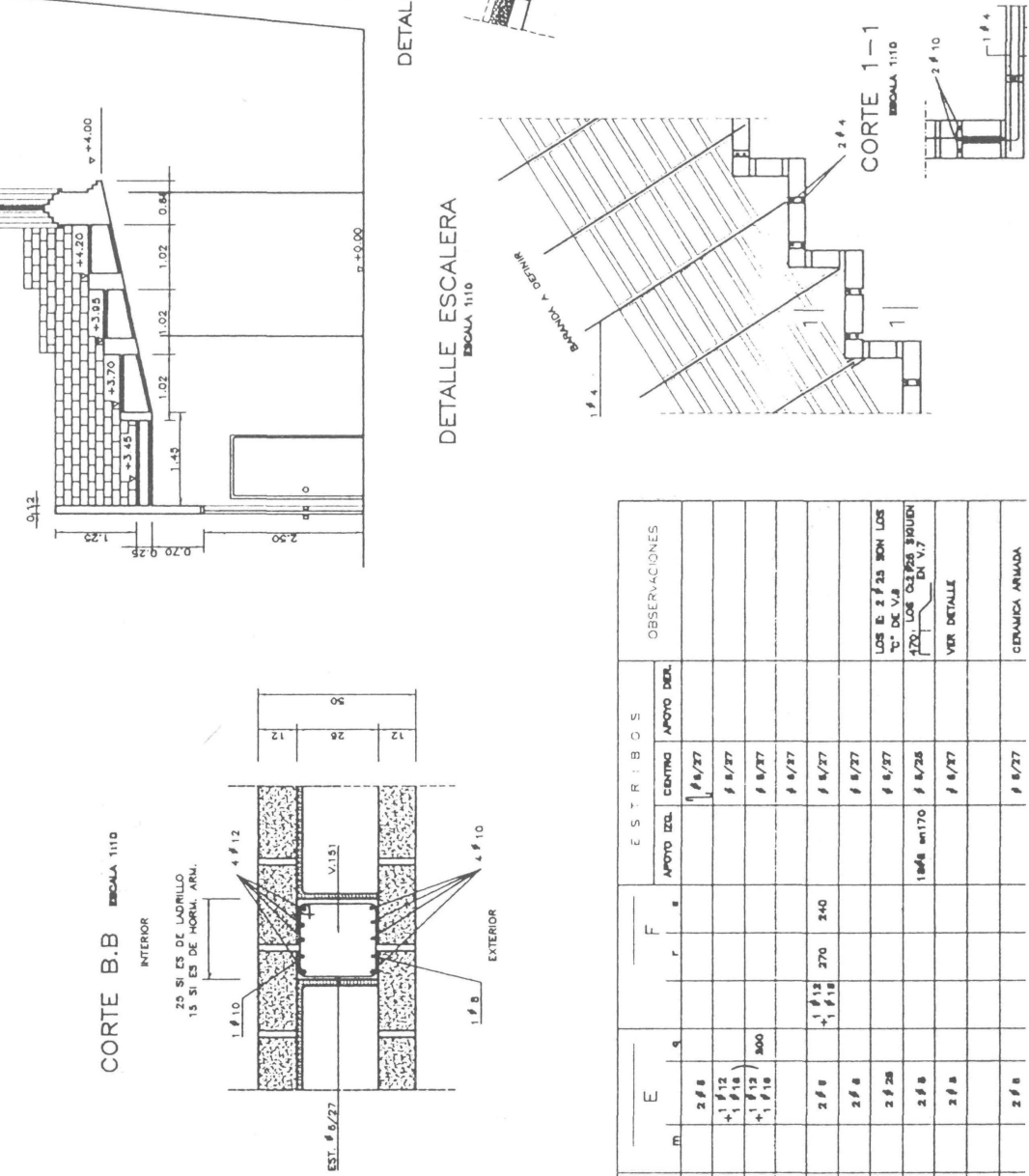

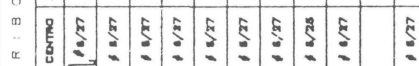

ज \&
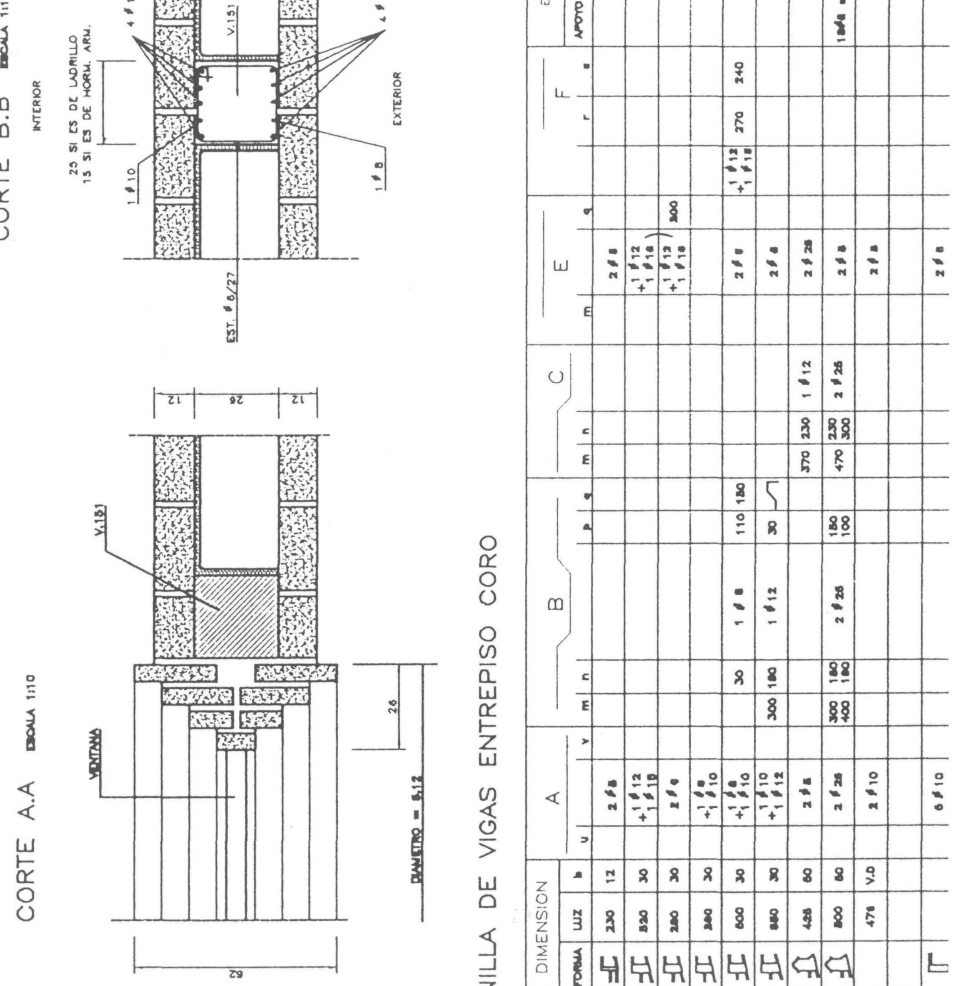
CUKIE A.A nom $1: 10$

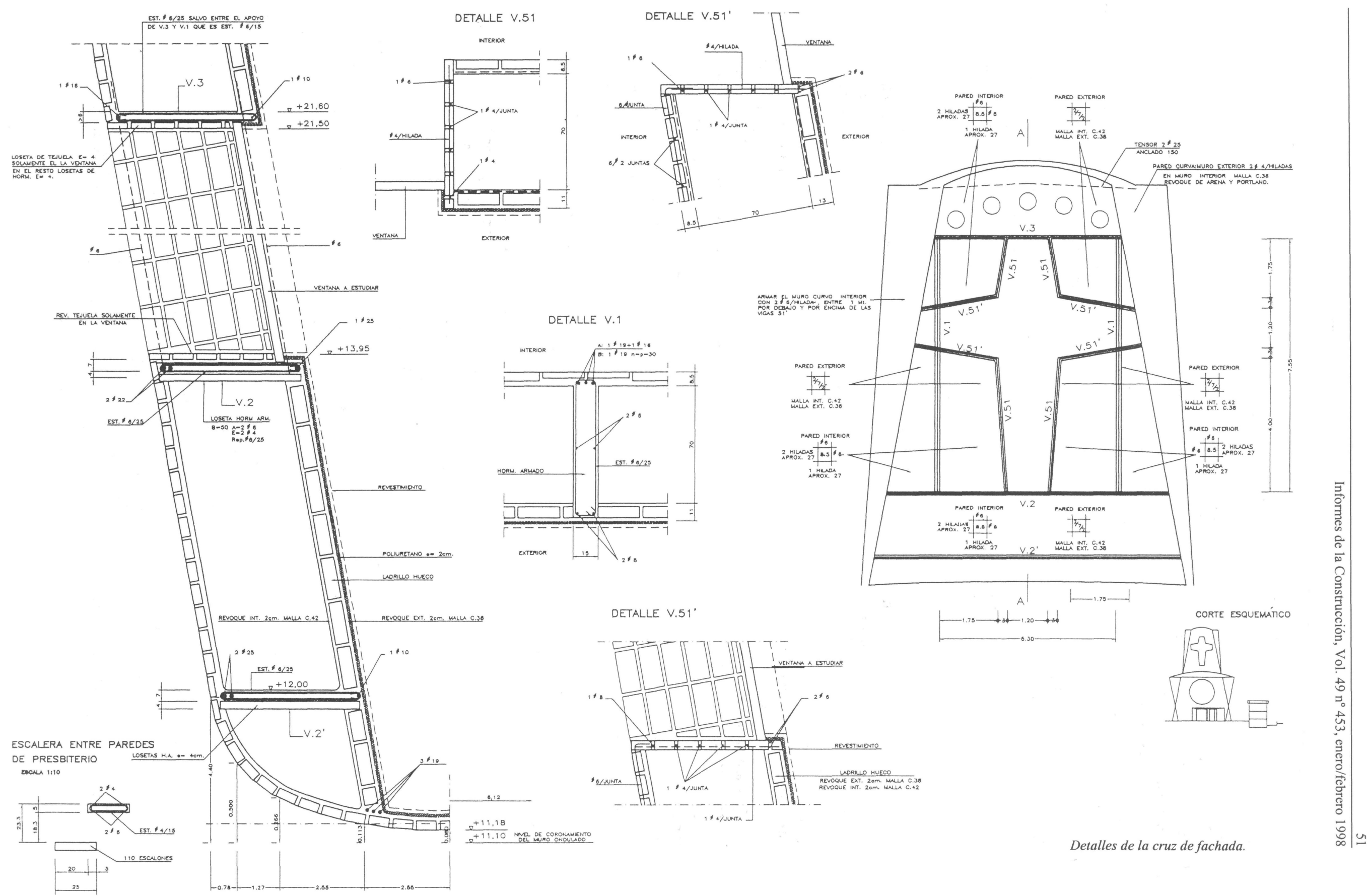


hasta la nueva posición, de nuevo con los gatos. Como operación final, se introducen en el enfoscado superior los redondos de tracción que van a "atar" las dos grandes vigas rígidas (que ya hemos indicado que, además, sirven de aleros) en el sentido transversal. El acabado proyectado es una capa de impermeabilización protegida por un ladrillo de $3 \mathrm{~cm}$ de espesor que actúa como acabado final de las bóvedas.

La altura de estas bóvedas es de $12 \mathrm{~m}$ sobre el suelo y tienen una luz media de $12 \mathrm{~m}$, llegando la máxima a algo más de $15 \mathrm{~m}$, mientras que la flecha oscila entre los $8 \mathrm{~cm}$ y $140 \mathrm{~cm}$ de máxima. En el espesor mínimo pueden alojarse los tensores que hemos indicado que resisten el empuje de las bóvedas y recogen los esfuerzos para evitar los dislocamientos de la estructura.

El coro se construyó mediante un forjado inclinado de ladrillo con la cara inferior de ladrillo "a tabla" y la superior a base de un encofrado con ladrillo que conformaban unas vigas en especie de "T". Todo el muro de cerramiento de la iglesia, en el que se encuentra el gran rosetón de vidrio, diseñado por Carlos Muñoz de Pablos, vitralista y presidente del Patronato de la Real Fábrica del Vidrio de la Granja en Segovia, es independiente, estructuralmente, del resto de los muros de la iglesia y así se manifiesta expresamente al no tocar en ningún momento a los mismos y articularse contra ellos a través de unos huecos cerrados con largos corridos de alabastro. Las instalaciones del edificio discurren por la cámara existente entre los dos muros a excepción de la calefacción, que lo hace a través de conductos enterrados bajo la solera.

Dieste siempre había manifestado sus dudas en cuanto a la imagen de la iglesia de Malvín en su fachada principal, llegando incluso a dibujar varias soluciones (junto con algunos artistas contemporáneos) que nunca llegaron a convencerle. Cuando se planteó la posibilidad de llevar a cabo este proyecto partiendo de los croquis de Malvín para San Juan de Ávila en Alcalá de Henares, buscamos la colaboración de Carlos Muñoz de Pablos y, de hecho, realizamos varias visitas a su taller, en compañía del pro- pio Dieste, con el fin de dar una solución a la fachada. El resultado de aquellos encuentros fue muy satisfactorio, ya que, además de poder incorporar a artistas plásticos contemporáneos a las nuevas iglesias, se estableció un diálogo que, sin duda, ha redundado en beneficio del proyecto. El rosetón, de seis metros de diámetro, ha sido diseñado como una lente, convexa hacia el exterior y cóncava hacia en interior, de forma que pudiera absorber los empujes y succiones del viento; al dar lugar a dos vidrieras distintas (una interior y otra exterior), produce un potente efecto de caleidoscopio según el observador se desplaza por el interior de la iglesia. Su geometría parte de uno de los despieces de la catedral de Chartres, situando en sus extremos la ruptura de forma y color en forma de estela. Además de todo lo anterior, la vidriera interior está abierta, sin vidrios, en los extremos del círculo, dejando "exento" el centro del mismo y creando un efecto de superposición y liviandad de la hoja interior. Los vidrios biselados potencian el efecto de diafragma de la luz, aumentando las fragmentaciones a favor del efecto caleidoscopio.

El presbiterio, se resuelve mediante el "doblado" de la curvatura de las cubiertas, dando lugar a una cruz tridimensional de más de un metro de espesor con ladrillos a tabla armados ligeramente y que conforman una estructura poligonal en dos dimensiones cubierta por otra vidriera de Carlos Muñoz de Pablos. Se remata con la colocación de un lucernario a base de 126 macetas ubicadas en la losa de hormigón. Junto al presbiterio, la sacristía se ha construido a base de una bóveda de arco de círculo, ejecutada con criterios muy parecidos a los expuestos, y con un lucernario cenital en forma de óculo, a través del cual se ve el cielo; su transposición en el despiece de ladrillo del suelo y la pieza central de piedra.

El ladrillo ha ofrecido desde hace milenios una lógica constructiva y una brillante capacidad de industrialización en su fabricación y montaje (se puede llegar hasta los $500 \mathrm{~kg} / \mathrm{m}^{2}$, livianos, deformables, aislantes, económicos, con mano de obra poco especializada, etc.). En España, desde los romanos, los árabes, su llegada a Hispanoamérica..., son fases de su permanente utilización

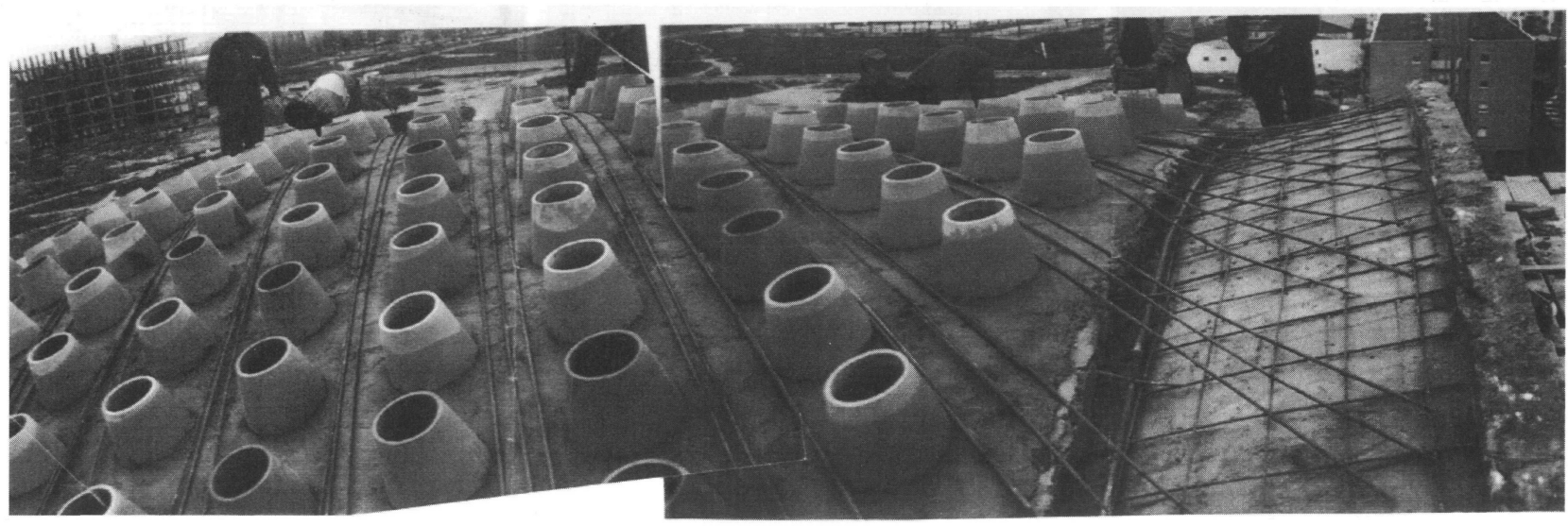

Montaje de la cubierta del presbiterio. 
en la historia de la construcción y del arte. Sin duda Dieste, ha profundizado quizá más racionalmente que la mayoría de los constructores o estudiosos de estas técnicas en las posibilidades del material. Pero, con ser esto importante, lo es aún más el sentido de la luz, de la forma, del proceso constructivo y de la economía. Su búsqueda estructural se acompaña siempre de nuevas experiencias plásticas y espaciales

\section{Ficha Técnica}

Ingeniería: Eladio Dieste. Dieste \& Montañez. Montevideo. Uruguay

Arquitectos: Carlos Clemente, Juan de Dios de la $\mathrm{Hoz}$

Arquitectos Técnicos: Andrés Carnicero, Luis de la Hoz, Lourdes García

Empresa Constructora: Construcciones Ramírez

Cerámica: Gres de Nava. Nava de Asunción, Segovia.

Vitralista: Carlos Muñoz de Pablos 